\title{
Clinical spectrum and cytogenetic analysis of Down syndrome patients attending a referral clinic in Jordan
}

M. Kawar, M. Dahabreh ${ }^{7}$ and A. Hawamdeh ${ }^{7}$

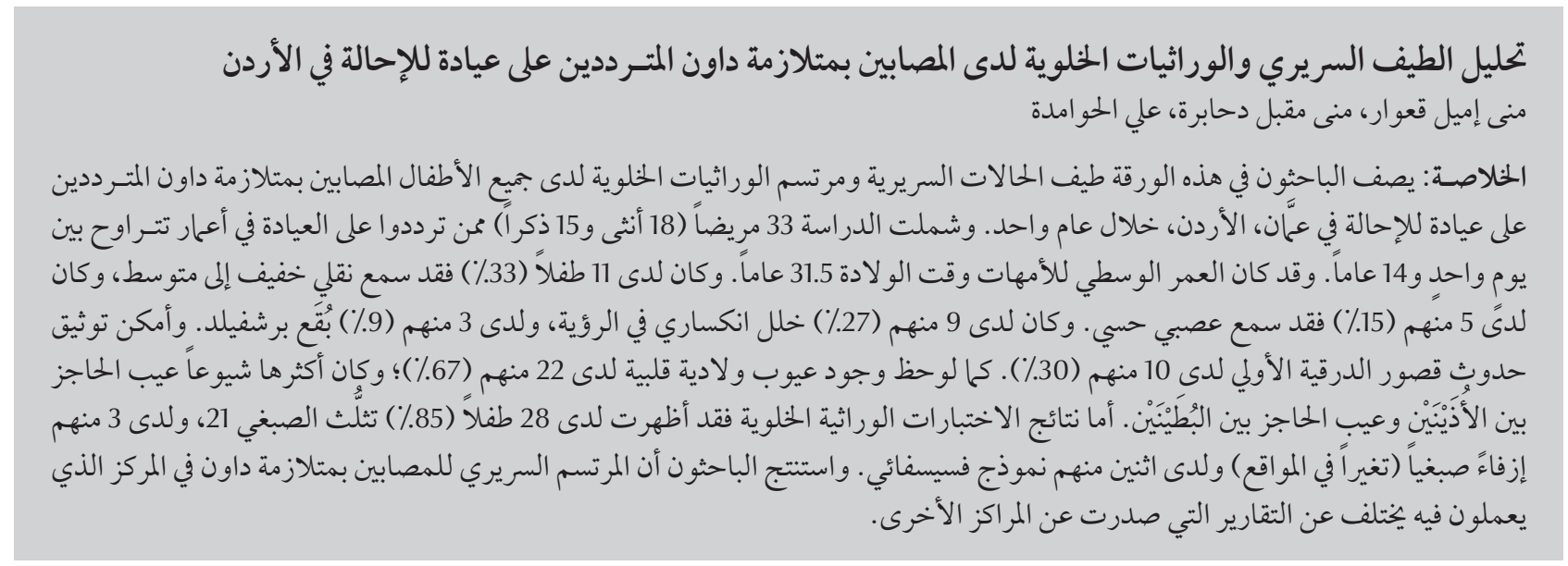

ABSTRACT The spectrum of medical conditions and the cytogenetic profile in all children with Down syndrome attending a referral clinic in Amman, Jordan over a 1-year period was described. A total of 33 patients (18 females, 15 males) attended, aged from day 1 to 14 years. Median maternal age at the time of delivery was 31.5 years. Eleven (33\%) children had a mild to moderate conductive hearing loss, 5 (15\%) had sensorineural hearing loss. $9(27 \%)$ had refractive error and $3(9 \%)$ showed Brushfield spots. Primary hypothyroidism was documented in $10(30 \%)$ children. Congenital cardiac defects were found in $22(67 \%)$ children; the most common was atrial or ventral septal defect. Cytogenetic testing results revealed that 28 (85\%) had trisomy 21 (3 had translocation and 2 showed mosaic pattern). The clinical profile of Down syndrome patients at our centre varies from reports from other centres.

Spectre clinique et analyse cytogénétique des patients atteints du Syndrome de Down en consultation dans une clinique de recours en Jordanie

RÉSUMÉ Le spectre des affections médicales et le profil cytogénétique de tous les enfants atteints du Syndrome de Down consultant dans une clinique de recours à Amman (Jordanie), pendant un an, ont été décrits. Au total, 33 patients (18 filles, 15 garçons), âgés d'un jour à 14 ans, ont été vus en consultation. L'âge médian de la mère à l'accouchement était de 31,5 ans. Onze enfants (33\%) souffraient d'une surdité de transmission légère à modérée et cinq enfants (15\%) étaient atteints d'une surdité neurosensorielle. Neuf enfants (27\%) étaient porteurs d'un vice de réfraction et trois enfants $(9 \%)$ présentaient des taches de Brushfield. Une hypothyroïdie primaire a été observée chez dix enfants (30\%). Des malformations cardiaques congénitales ont été diagnostiquées chez 22 enfants (67\%), la communication interauriculaire ou interventriculaire étant la pathologie la plus fréquente. Les résultats des analyses cytogénétiques ont révélé que 28 enfants (85\%) étaient porteurs de trisomie 21 (trois cas par translocation et deux cas en mosaïque). Le profil clinique des patients atteints du Syndrome de Down dans notre centre diffère des rapports issus des autres centres. 


\section{Introduction}

Down syndrome is one of the most common chromosomal disorders in children and is considered the leading cause of noninherited mental retardation [1]. The prevalence has been reported in some studies to be 1/800 [1].

Down syndrome involves different body systems $[1,2]$. Not only do these children have characteristic physical features, they also have multiple medical conditions and malformations $[3,4]$. The occurrence of these malformations varies across different studies [4].

The genetics clinic at King Hussein Medical Centre was the first in Amman. It accepts patients from different centres and hospitals from all over Jordan. This study was important to check the pattern of referred cases and to compare it with that of other centres.

The purpose of this case series was to describe the spectrum of medical conditions and cytogenetic profile of children with Down syndrome referred to a genetic clinic in Amman, Jordan.

\section{Methods}

A prospective study was conducted on all children with the diagnosis of Down syndrome who were referred to the genetics clinic at King Hussein Medical Centre, Amman, Jordan, from January 2004 to January 2005. A total of 33 patients were included, aged from 1 day to 14 years.

The data collected included maternal and paternal age at diagnosis. Thyroid function tests, ophthalmology examination and hearing assessment tests were performed for all patients. All children had a cardiac review and echocardiography examination. Chromosomal testing was done for all those included.

Ethical committee approval for the study was obtained.

\section{Results}

There were 33 children with Down syndrome who attended the genetics clinic during the study period: 18 (55\%) females and 15 (45\%) males). The median maternal age at the time of delivery was 31.5 years; $10(30 \%)$ mothers were aged 17-20 years, 15 (45\%) were $20-35$ years and 8 (25\%) were 36-46 years.

Normal hearing results were found in $17(52 \%)$ children, 11 (33\%) had mild to moderate conductive hearing loss, while $5(15 \%)$ had sensorineural hearing loss. Eye examinations showed that $9(27 \%)$ had refractive error and 3 (9\%) had Brushfield spots.

Primary hypothyroidism was documented in 10 (30\%) children; 2 of our patients developed hypothyroidism at an older age but none of them had autoimmune antibodies. Congenital cardiac defects were found in 22 (67\%) children. Cyanotic congenital heart disease was found in less than 5\%: the most common was atrial or ventricular septal defect in 20/22 of these cases (90\%)

Cytogenetic testing results revealed that $28(85 \%)$ had trisomy $21 ; 3(9 \%)$ had translocation, 1 of which was a de novo 21,21 translocation, and $2(6 \%)$ showed mosaic pattern.

\section{Discussion}

There is a well established relationship between older maternal age and increased incidence of Down syndrome in the offspring [5]. In our study the median maternal age at the time of delivery was 31.5 years. This is consistent with a study in Dubai where the mean age was 33.5 years [6]. The mean maternal age in a study by Kava et al. in India was 26.8 years [5]. This may be explained by the higher fertility rate in this younger reproductive age group. A high proportion of the mothers in our case series
(45\%) were between 20 and 30 years of age. These mothers are considered to be at low risk and do not usually undergo antenatal screening. Mothers who would usually be considered as high risk (above 35 years of age) formed only $25 \%$ of our study group.

Nondisjunction (trisomy 21) is the most common genetic defect found in Down syndrome [7] and we found this in $85 \%$ of cases; mosaic pattern was found in 2 patients (6\%). This is higher than that reported worldwide (< 1\%) $[7,8]$. This may be explained by the small number of patients studied. One of our patients had de novo 21,21 translocation.

There is a well known risk of autoimmune diseases in these children, involving both the endocrine and the nonendocrine systems $[3,4]$. The most common autoimmune disease in Down syndrome is related to the thyroid gland [9]. The current recommendations are to screen annually for thyroid function in children with Down syndrome [9]. Congenital hypothyroidism has been reported to be about 30 times more common in Down syndrome [9] and $8 / 33$ patients in our study had congenital hypothyroidism, while 2 patients acquired hypothyroidism at an older age. In contrast to our findings, Karlsson in Sweden had no cases of congenital hypothyroidism in his study group of 85 patients [10]. He also demonstrated a gradual increase in the concentrations of thyroid autoantibodies from the age of 8 years.

All children with Down syndrome, even if clinically asymptomatic, should undergo 2D echocardiography [11]. We found congenital cardiac defects in $22 / 33(67 \%)$ of our children. Cyanotic congenital heart disease was found in less than $5 \%$. The most common was atrial or ventricular septal defect in 20 of these cases. This is higher than figures reported worldwide (50\%) [11]. Kava et al. in a study of 524 Down syndrome 
patients in India reported an incidence of congenital heart disease of $18 \%$, with $25 \%$ of these cases having ventricular septal defect [5].

In general most patients with Down syndrome have Brushfield spots during eye examination. In our case series $9 \%$ of patients had Brushfield spots. Interestingly, none of the patients with Down syndrome in a Hong Kong University study had Brushfield spots [12]. This is also consistent with the results in a Korean population [13]. This can be explained by the high prevalence of dark eyes in our population. Wallis has suggested that there is a low prevalence of Brushfield spotsin blue or light-coloured eyes that darken with age [14]. Refractive errors have been demonstrated in $70 \%$ of Down syndrome patients [14].
We found such errors in 27\% of cases, which is less than what was reported in Hong Kong (58\%) [12].

Disorders of the ear, nose and throat may hinder children with Down syndrome from reaching their developmental potential [8]. Mild to moderate conductive hearing loss was seen in 11 children (33\%) in our study. This is less than the 50\% reported in 26 patients screened in Saudi Arabia [15]. Hearing loss in Down syndrome patients may be due to recurrent otitis media, eustachian tube dysfunction or middle ear ciliary defects [15]. Balkany et al. reported that $78 \%$ of patients with Down syndrome had evidence of hearing loss [16]. Five (15\%) of our studied group had sensorineural hearing loss. None of these patients showed other neurological deficits.

Down syndrome is a predisposing factor for sleep-related breathing disorders, and up to $80 \%$ of children were found to have sleep apnoea disorders [17]. Such disorders were not studied in our study group as we have limited access to sleep studies in addition to financial limitations.

\section{Conclusions}

The clinical profile of Down syndrome patients at our centre varies, and is quite different from many other centres. The complexity of the medical conditions requires a multidisciplinary team approach and structured protocols.

\section{References}

1. Jorgenson RJ. Down syndrome. Medicineonline. (http://www. medicineonline.com/topics/D/2/Down-Syndrome.html, accessed 19 October 2010).

2. Bianca S. Non congenital heart disease aspects of Down syndrome. Images in Paediatric Cardiology, 2002, 13:3-11.

3. Chen $\mathrm{MH}$ et al. Thyroid dysfunction in patients with Down syndrome. Acta Paediatrica Taiwanica, 2007, 48:191-195.

4. Dzurova D, Pikhart H. Down syndrome, paternal age and education: comparison of California and the Czech Republic. BMC Public Health, 2005, 5:69.

5. Kava MP et al. Down syndrome: clinical profile from India. Archives of Medical Research, 2004, 35:31-35.

6. Murthy SK et al. Incidence of Down syndrome in Dubai, UAE. Medical Principles and Practice, 2007, 16:25-28.

7. Hindley D, Medakkar S. Diagnosis of Down syndrome in neonates. Archives of Disease in Childhood: Fetal and Neonatal, 2002, 87:F220-F221.

8. Mitchell RMD, Call EMS, Kelly J. Ear, nose and throat disorders in children with Down syndrome. Laryngoscope, 2003, 113:259-263.

9. Roizen NJ. The early interventionist and the medical problems of the child with Down syndrome. Infants and Young Children, 2003, 16(1):88-95.
10. Karlsson B et al. Thyroid dysfunction in Down's syndrome: relation to age and thyroid autoimmunity. Archives of Disease in Childhood, 1998, 79:242-245.

11. Behrman RE, Kliegman R, Jenson B. Nelson textbook of pediatrics, 16th ed. Philadelphia, WB Saunders, 2000.

12. Wong V, Ho D. Ocular abnormalities in Down syndrome: an analysis of 140 Chinese children. Pediatric Neurology, 1997, 16:311-314.

13. Kim $\mathrm{JH}$ et al. Characteristic ocular findings in Asian children with Down syndrome. Eye (London, England), 2002, 16:710714.

14. Wallis HRE. The significance of Brushfield's spots in the diagnosis of mongolism in infancy. Archives of Disease in Childhood, 1951, 26:495-500.

15. Kattan HA, Jarrar RF, Mahasin ZZ. A pilot study of the relationship between Down's syndrome and hearing loss. Saudi Medical Journal, 2000, 21:931-933.

16. Balkany T et al. Hearing loss in Down's syndrome. A treatable handicap more common than generally recognized. Clinical Pediatrics, 1979, 18:116-118.

17. Fitzgerald DA, Paul A, Richmond C. Severity of obstructive apnoea in children with Down syndrome who snore. Archives of Disease in Childhood, 2007, 92:423-425. 